\title{
Strongly acidic mesoporous aluminosilicates prepared from zeolite seeds: acylation of anisole with octanyl chloride
}

\author{
Pei-Chun Shih $^{\mathrm{a}, \mathrm{b}}$, Jung-Hui Wang ${ }^{\mathrm{b}}$, Chung-Yuan Mou ${ }^{\mathrm{b}, *}$ \\ ${ }^{\text {a }}$ Ching Kuo Institute of Management and Health, Keelung 203, Taiwan \\ ${ }^{\mathrm{b}}$ Department of Chemistry, Center of Condensed Matter Science, National Taiwan University, Taipei 106, Taiwan
}

Available online 15 July 2004

\begin{abstract}
Ultrastable acidic mesoporous aluminosilicates (MCM-48-S, MCM-48-SH, MCM-41-S) with mesostructures, strong acidity, and high hydrothermal stability was synthesized from assembly of cetyltriammonium bromide (CTAB) and pre-formed zeolite Beta seed. The catalytic application of the solid acid catalysts (HMCM-41-S and HMCM-48-SH) was demonstrated with the Friedel-Crafts acylation of aromatics. High conversion (>90\%) and high selectivity (100\%) were obtained.
\end{abstract} (C) 2004 Elsevier B.V. All rights reserved.

Keywords: Zeolite seed; Mesoporous aluminosilicates; Acylation; Anisole

\section{Introduction}

Mesoporous aluminosilicates have attracted much recent attention because of their potential use as versatile catalysts and catalyst supports, especially for large molecules [1]. Compared with conventional zeolites, MCM-41 and MCM-48 have weaker acidity and much less hydrothermal stability which limit their catalytic applications. The relatively low acidity of mesoporous materials such as MCM-41, as compared to zeolites, can be attributed to the amorphous nature of the pore walls.

Recently, two research groups succeeded in synthesizing mesoporous aluminosilicates with high acidity and hydrothermal stability [2-4]. The success relies on the formation of better-structured wall with pre-formed zeolitic nanocluster. They used zeolite seeds made from quaternary alkyl ammonium salts as silica precursor to make the mesoporous materials with surfactants as templates. The success relies on formation of better-structured wall with pre-formed zeolitic nanocluster. The mesotructures reported for these type of stable acidic mesoporous materials are hexagonal [2-4], cellular foam [5], and large-pore hexagonal [6]. The strategy of prior developments of zeolite nanocluster for

\footnotetext{
${ }^{*}$ Corresponding author. Fax: +886 223660954.

E-mail address: cymou@ntu.edu.tw (C.-Y. Mou).
}

making mesoporous silica is robust and general. Recently, we have reported the corresponding three-dimensional bicontinuous cubic (Ia3d), denoted as, MCM-48-S [7]. We employed the beta-zeolite seeds, which were produced by using tetraethylammonium hydroxide (TEAOH) as the structure-directing agent, as the silica source. A similar method of preparing MCM-48 with enhanced acidity has also been reported [8]. These materials possess very high hydrothermal stability and strong acidity.

The new materials will be useful in many catalytic applications taking advantage of its stronger acidity. Up to the present, the test reactions are mostly cracking reactions, cumene cracking [2] or tri-isopropylbenzne [3,9,10]. Those reactions normally require acidic sites of intermediate strength. It would be desirable to extend applications where stronger acidity and mesoporosity are required.

The Friedel-Crafts acylation of aromatics is a widely used reaction for the production of many pharmaceutical, agrichemical, and fragrant compounds [11]. The acid catalyzed acylation of aromatics is the main route for the formation of aromatic ketone, an important intermediate in the pharmaceutical and flavor industry. Conventional Friedel-Crafts methodology calls for Lewis acids such as metal halides and some strong Brønsted acids such as polyphosphoric and sulfuric acid as the catalysts [11]. In order to eliminate the corrosion and environmental problems, many efforts are being made to find solid acid catalysts which can successfully 
carry out acylation with a more environmental-friendly technology [12-15].

In this paper to study the acylation reaction of anisole with octanoyl chloride as in sized by hydrothermally treating the mixture of pre-formed zeolitic nanocluster and surfactant solution $\left(\mathrm{C}_{16} \mathrm{TMAB}\right)$ at $150{ }^{\circ} \mathrm{C}$ for $2-6 \mathrm{~h}$, then adjusting the $\mathrm{pH}$ value to 10.0 and

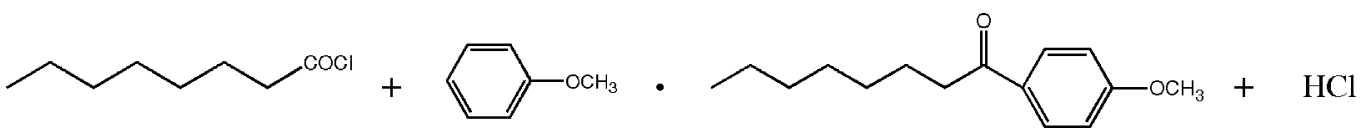

It is known that zeolite Beta is an effective catalyst for the acylation of aromatic compounds. Thus it is desirable to carry out the reaction on the mesoporous aluminosilicates, MCM-41-S and MCM-48-S, made from zeolite Beta seeds. Previously, the acylation of anisole by octanoic acid has been investigated on BEA coating of structured supports [16] and acid leached zeolite Beta [17]. It is proposed that the catalysis occurred on strong Lewis acid sites on the zeolite Beta and the mesoporosity enhanced the catalytic action. The acylation reaction catalyzed by solid acid seems to be internal diffusion-limited in zeolites [15]. The use of mesoporous solid acids would improve the transport of the reactants, especially for the relatively large molecules as octanoyl chloride used in this work.

In this paper we will report the synthesis and characterization of MCM-41-S and MCM-48-S with the zeolite Beta seeds. The acidity and the distribution of acid sites were evaluated by temperature programmed desorption (TPD) of ammonia and X-ray photoelectron spectroscopy (XPS) of chemisorbed pyridine. Finally we report the acylation of anisole on octanoyl chloride with those catalysts.

\section{Experimental}

\subsection{Materials and syntheses}

Fumed silica (from Sigma), tetraethylammonium hydroxide (TEAOH, 20\% aqueous solution from Acros), cetyltrimethylammonium bromide ( $\mathrm{C}_{16}$ TMAB from Acros) and sodiumaluminate (from Riedel-de-Haen) were used as received.

Synthesis of pre-formed zeolitic nanocluster:zeolitic nanoclusters were prepared by mixing $\mathrm{NaAlO}_{2}, \mathrm{NaOH}$, fumed silica, TEAOH aqueous solution, and water at $50{ }^{\circ} \mathrm{C}$ for $2-5 \mathrm{~h}$, then the solution was hydrothermally heated at $100^{\circ} \mathrm{C}$ for $18 \mathrm{~h}$. A clear solution of nanoprecursors was obtained.

Three strongly acidic mesoporous aluminosilicates denoted as MCM-48-S, MCM-48-SH, and MCM-41-S were hydrothermally synthesized by mixing the pre-formed zeolitic nanocluster and surfactant solution ( $\left.\mathrm{C}_{16} \mathrm{TMAB}\right)$. MCM-48-S was synthesized by the reaction of zeolitic nanocluster with cetyltrimethylammonium bromide solution at $150{ }^{\circ} \mathrm{C}$ for $6-24 \mathrm{~h}$. Well-ordered MCM-48-SH (the extra $\mathrm{H}$ denotes re-hydrothermal treatment) was obtained by adjusting the $\mathrm{pH}$ value of the as-synthesized MCM-48-S precursor to 10.0 with $1.2 \mathrm{M} \mathrm{H}_{2} \mathrm{SO}_{4}$ and then hydrothermally treating the mixture at $100{ }^{\circ} \mathrm{C}$ for 2 days. MCM-41-S was synthe- hydrothermally treating the precursor again at $100^{\circ} \mathrm{C}$ for 2 days. All the samples were collected by filtration, washed with water, dried at $100{ }^{\circ} \mathrm{C}$ oven for $6 \mathrm{~h}$, and calcined at $580{ }^{\circ} \mathrm{C}$ for $6 \mathrm{~h}$. For the purpose of comparison among samples, the $\mathrm{Al} / \mathrm{Si}$ ratio of all samples, including the standard MCM-48, were fixed at 1/37. The molar ratios of reactants $\mathrm{NaAlO}_{2}: \mathrm{SiO}_{2}: \mathrm{NaOH}: \mathrm{TEAOH}: \mathrm{C}_{16}$ TMAB: $\mathrm{H}_{2} \mathrm{O}$ were 1:37:1.5-9:11-22:18.3:3000-3500.

The proton form of the mesoporous materials (HMCM-48S, HMCM-48-SH, and HMCM-41-S)was prepared at $80^{\circ} \mathrm{C}$ by ion exchange with $0.1 \mathrm{M} \mathrm{NH}_{4} \mathrm{Cl}$, followed by calcination at $500{ }^{\circ} \mathrm{C}$ for $2 \mathrm{~h}$.

\subsection{Characterization}

The powdered X-ray diffraction patterns were recorded on a Scintag X1 diffractometer using $\mathrm{Cu} \mathrm{K} \alpha(\lambda=0.154 \mathrm{~nm})$ radiation. The $\mathrm{N}_{2}$ adsorption-desorption isotherms were obtained on a Micromeritics ASAP 2010 sorptometer at $77 \mathrm{~K}$. The infrared spectra were measured on MAGNA-IR 500 spectrometer in the range of $400-4000 \mathrm{~cm}^{-1}$ with a resolution of $2 \mathrm{~cm}^{-1}$. The $\mathrm{NH}_{3}$-TPD-MASS curves were determined in the range $110-800^{\circ} \mathrm{C}$ at a heating rate of $10^{\circ} \mathrm{C} / \mathrm{min}$ on an AutoChem 2910 and Thermo ONIX ProLab system.

$\mathrm{X}$-ray photoelectron spectroscopic analyses of chemisorbed pyridine on the HMCM-48-SH catalyst were performed using a Thermo VG Scientific, ESCALAB 250 fitted with a monochromatic $\mathrm{Al} \mathrm{K} \alpha$ radiation $(1486.8 \mathrm{eV}) \mathrm{X}$-ray source, under a residual pressure of $\sim 10^{-7} \mathrm{~Pa}$. Calibration was achieved by setting the $\mathrm{Si} 2 \mathrm{p}$ binding energy at $103.0 \mathrm{eV}$. Before loading the organic base, the catalyst was pretreated at $450{ }^{\circ} \mathrm{C}$ for $12 \mathrm{~h}$ to remove adsorbed water and organic contaminants, and then cooled down to room temperature and impregnated with a solution of pyridine by ultrasonification. Then the materials were pretreated at $150^{\circ} \mathrm{C}$ for $12 \mathrm{~h}$ to ensure complete chemisorbed pyridine on the surface.

\subsection{Catalytic reaction-acylation of anisole with octanoyl chloride on mesoporous materials}

The catalytic reaction was operated (Eq. (1)) in a slurry system (with a reaction volume of $25 \mathrm{ml}$ ) with a batch reflux configuration. The system was purged with nitrogen to expel air and moisture. The concentration of octanoyl chloride in anisole was $0.2 \mathrm{~mol} / \mathrm{l}$, and the amount of catalyst (mesoporous material) used was $0.15 \mathrm{~g}$. Tetradecane was added as 


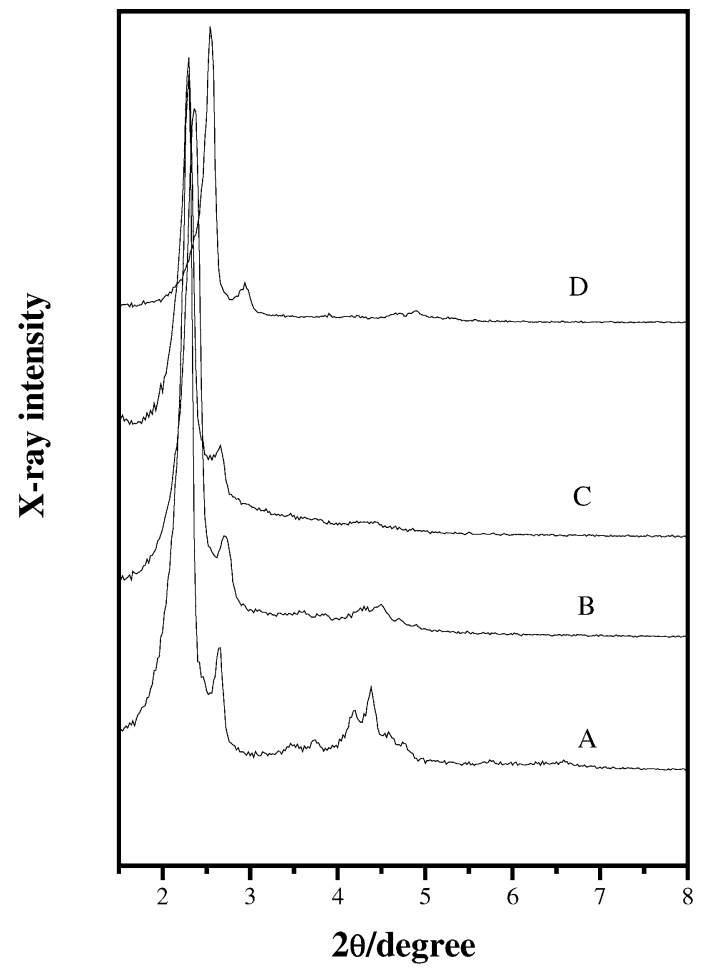

Fig. 1. The XRD patterns of MCM-48-SH (A) calcined; (B), (C) soaked in boiling water for 5 and 10 days; (D) treated in $800^{\circ} \mathrm{C}$ steam for $4 \mathrm{~h}$.

a GC internal standard. The reaction temperature was taken as the refluxing temperature of anisole $\left(155^{\circ} \mathrm{C}\right)$. Reaction mixture was sampled with a syringe every $30-60 \mathrm{~min}$ and GC analyzed.

\section{Results and discussion}

\subsection{Synthesis and characterization}

Fig. 1A is the XRD pattern of MCM-48-SH which shows a well-defined set of diffraction peaks that were assigned to the (2 1 1), (220), (321), (400), (420), (322), (422), and (431) peaks of the cubic space group Ia3d. We did not find any diffraction peak in the region of higher angles $(2 \theta$ $\left.=10-40^{\circ}\right)($ not shown here), and this implied that the material is a pure phase. The MCM-48-SH materials possess excellent hydrothermal stability. They show well-ordered cubic ( $I a 3 d)$ mesostructures even after soaked in boiling water for 10 days (Fig. 1C) or after treated in $800^{\circ} \mathrm{C}$ steam for $4 \mathrm{~h}$ (Fig. 1D). There is only limited decay of structure. Table 1 lists the physical properties of the products that were treated in boiling water for different time. The MCM-48-SH possesses a BET surface area around $1152 \mathrm{~m}^{2} / \mathrm{g}$, a high pore volume about $1.06 \mathrm{~cm}^{3} / \mathrm{g}$, and the average pore diameter is about $27 \AA$. The BET surface area and pore volume of MCM-48-SH show smaller reduction (15-20\%) after treated in $800{ }^{\circ} \mathrm{C} 20 \%$ steam for $4 \mathrm{~h}$ or after 5-day hydrothermal treatment and it stays nearly the same to 10 days. The wall thickness slowly increases as the time of re-hydrothermal treatment increases. Previously Ryoo and coworkers showed that the hydrothermal stability of MCM-48 could be improved by treating the as-synthesized sample in hot $\mathrm{NaCl}$ solution for prolonged period (up to 20 days) [18]. However, their hydrothermal stability test in boiling water was for only $12 \mathrm{~h}$.

Fig. 2 is the XRD pattern of MCM-41-S that shows good hexagonal phase $(P 6 m m)$. It exhibits the same high hydrothermal stability as MCM-48-SH Fig. 2C and D). The sample has a BET surface area around $1155 \mathrm{~m}^{2} / \mathrm{g}$, a high pore volume about $1.11 \mathrm{~cm}^{3} / \mathrm{g}$, and the average pore diameter is about $25 \AA$ (Table 1). These physical data of mesoporousity are close to those reported by Zhang et al. [3] for MAS-5, with one major difference. We further took the IR spectrum (Fig. 3) of MCM-48-S. The sharp absorption peaks at $500-550 \mathrm{~cm}^{-1}$ observed indicate the presence of five-member ring structure for the siloxane connections [3] that is characteristic of the zeolite seeds. In contrast, the standard MCM-48 synthesized from aluminate silicates does not possess this special feature in IR. We measured the MAS NMR chemical shift of the tetrahedral site of ${ }^{27} \mathrm{Al}$ (figure not shown here) for MCM-48-S at $53.8 \mathrm{ppm}$ which is close to that of zeolite BEA (at $54.5 \mathrm{ppm}$ ). From the ${ }^{27} \mathrm{Al} \mathrm{NMR}$ data, we can also account for the special strong wall structure.

The acidity of the samples was determined by measuring the $\mathrm{NH}_{3}$-TPD-MASS desorption curves of the H-form of

Table 1

Comparison of physical characteristics of various products treating in boiling water for different time

\begin{tabular}{|c|c|c|c|c|c|}
\hline Samples treated in boiling water & Surface area $\left(\mathrm{m}^{2} / \mathrm{g}\right)$ & Pore size $(\AA)$ & Pore volume $\left(\mathrm{cm}^{3} / \mathrm{g}\right)$ & $a_{0}(\AA)$ & $h(\AA)$ \\
\hline MCM-48 & 1322 & 23.5 & 0.87 & 89.4 & 17.2 \\
\hline Untreated MCM-41-S & 1155 & 25.0 & 1.11 & 92.5 & 17.4 \\
\hline For 5 days & 960 & 23.0 & 0.85 & 91.0 & 18.6 \\
\hline For 10 days & 855 & 19.5 & 0.59 & 94.0 & 20.8 \\
\hline $800^{\circ} \mathrm{C} 20 \%$ steam for $4 \mathrm{~h}$ & 847 & 18 & 0.46 & 83.8 & 18.1 \\
\hline Untreated MCM-48-SH & 1152 & 27.0 & 1.06 & 94.0 & 17.0 \\
\hline For 5 days & 970 & 23.0 & 0.86 & 91.6 & 18.2 \\
\hline For 10 days & 914 & 21.0 & 0.75 & 94.0 & 19.9 \\
\hline $800^{\circ} \mathrm{C} 20 \%$ steam for $4 \mathrm{~h}$ & 978 & 18.0 & 0.53 & 85.1 & 18.6 \\
\hline
\end{tabular}




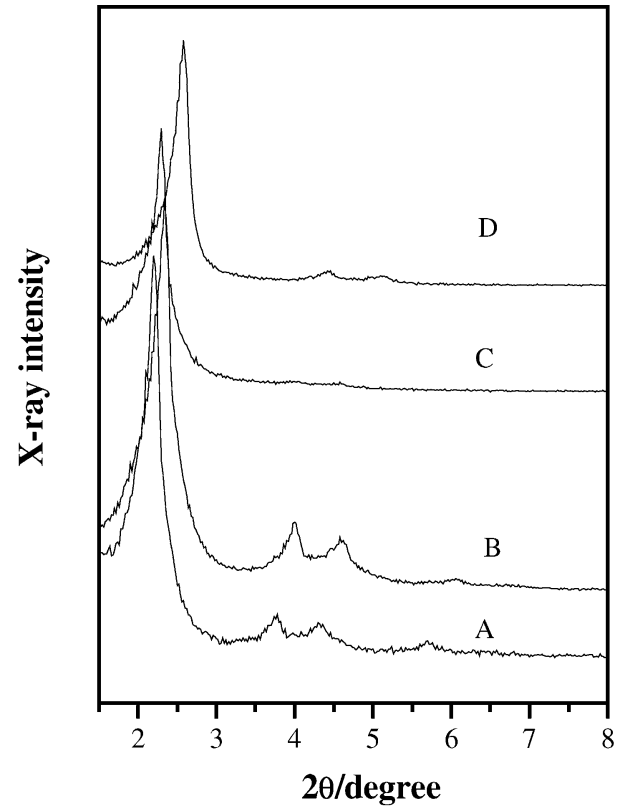

Fig. 2. The XRD patterns of MCM-41-S (A) as synthesized; (B) calcined; (C) soaked in boiling water for 10 days; (D) treated in $800^{\circ} \mathrm{C}$ steam for $4 \mathrm{~h}$.

MCM-48-SH and MCM-41-S (Fig. 4). $\mathrm{NH}_{3}$-desorption lasts until a fairly high temperature of $500^{\circ} \mathrm{C}$, much higher than that of typical MCM- 48 at $320^{\circ} \mathrm{C}$ [3]. The high temperature for $\mathrm{NH}_{3}$ desorption is similar to the desorption temperature of the acidic HZSM-5. We thus have a fairly acidic mesoporous aluminosilicates in MCM-48-SH and MCM-41-S.

In the 1970s, Defosse and Canesson [19] used X-ray photoelectron spectroscopy (XPS) technology to study the nature and strength of acid sites present in zeolite $\mathrm{Y}$ by determining the position and intensity of the $\mathrm{N} 1 \mathrm{~s}$ peak of

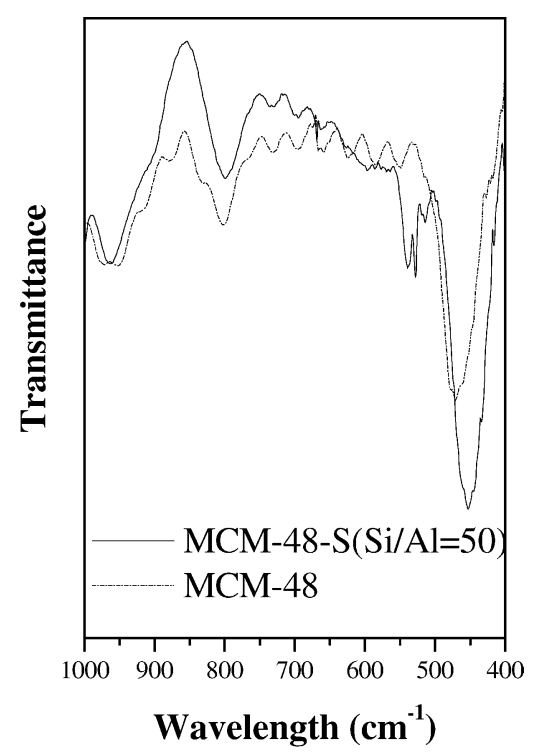

Fig. 3. Infra-red spectrum of calcined MCM-48-S and MCM-48.

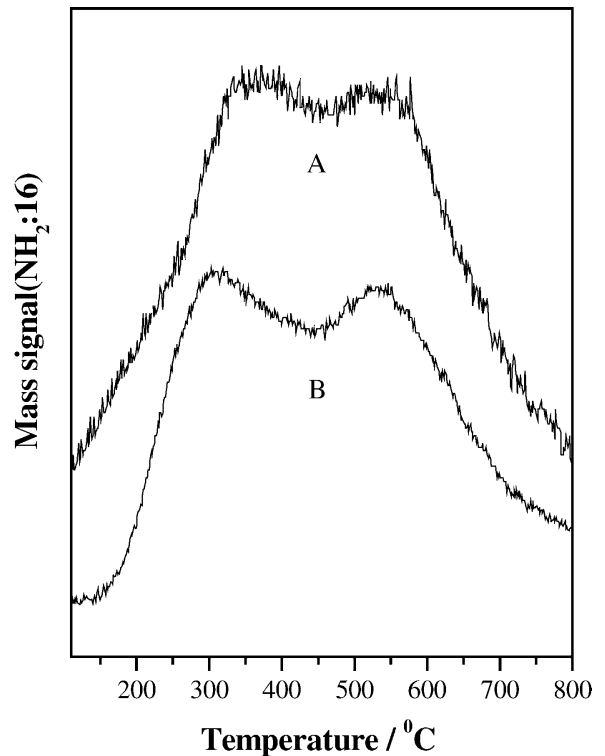

Fig. 4. The $\mathrm{NH}_{3}$-TPD-MASS curves of samples (A) HMCM-41-S; (B) HMCM-48-SH.

an adsorbed organic base. Since then, several workers have extended this technique to study of other zeolitic materials [20,21]. Santiesteban et al. [22] have used this technology to study the nature and relative strength of acid sites of $\mathrm{WO}_{x} / \mathrm{ZrO}_{2}$ catalysts. XPS should be a suitable technique to determine the nature (Brønsted and/or Lewis) and relative strength of acid sites of our mesoporous materials. The XPS spectra were recorded in the $390-415 \mathrm{eV}$ regions to determine the binding of $\mathrm{N} 1 \mathrm{~S}$ electron in the sample. Fig. 5 shows the N 1s XPS spectrum obtained on the HMCM-48-SH catalyst loaded with pyridine. The spectra can be de-convoluted into three bands (50\% Gaussian, 50\% Lorentzian) as shown in Fig. 5 and Table 2. We use the previous assignment [22] of peak I corresponding to a strong Brønsted acid site, peak II corresponding to a weak Brønsted acid site and peak III corresponding to a strong Lewis acid site. The data indicate that weak Brønsted acid site and Lewis site are the predominant acid sites on the surface of the HMCM-48-SH (both are

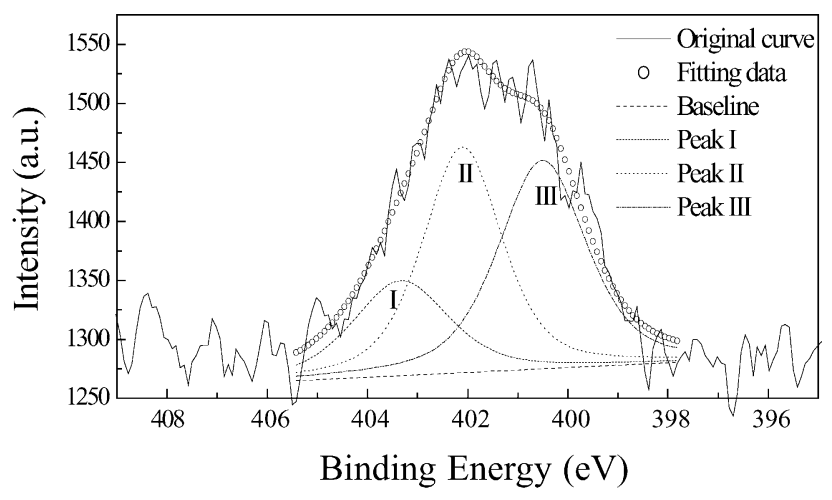

Fig. 5. N 1s photoelectron spectra of pyridine chemisorbed on HMCM-48-SH. 
Table 2

Binding energies and relative concentration of $\mathrm{N} 1 \mathrm{~s}$ components of pyridine chemisorbed on HMCM-48-SH

\begin{tabular}{llll}
\hline Component & $\begin{array}{l}\text { Binding } \\
\text { energy }(\mathrm{eV})\end{array}$ & $\begin{array}{l}\text { Relative } \\
\text { concentration }(\%)\end{array}$ & Acid site type \\
\hline Peak I & 402.3 & 20.1 & Strong Brønsted \\
Peak II & 401.1 & 39.3 & Weak Brønsted \\
Peak III & 399.5 & 40.6 & Lewis \\
\hline
\end{tabular}

about $40 \%$ ) and strong Brønsted acid sites are about $20 \%$. Thus the total amount of strong acids (peaks I and II) is just a little larger than that of weak Brønsted acid. This is roughly (the data is only semi-quantitative) in consistent with the two bands of acid strength observed in $\mathrm{NH}_{3}$-TPD desorption experiment. Compared to other strong acid system, tungstated zirconia for example [22], our HMCM-48-SH materials show a much higher acid strength with high percentage of Lewis acid. The Lewis acid sites probably help more in the catalysis of acylation since this reaction is known to be well catalyzed by homogeneous Lewis acids.

\subsection{Catalytic reaction}

We now report the results of the catalytic reaction of Eq. (1). From the results of GC-MS analyses, the selectivity of the reaction is close to $100 \%$ for the para-substituted aromatic ketone. No other side-product (such as phenyl carboxylic ester or products of de-methylated anisole) was observed. Beers et al. recently reported [15] the acylation of anisole by octanoic acid with zeolite-coated monoliths as catalyst, and they always have side products with their selectivities ranging from $44 \%$ to $98 \%$ (58\% to $86 \%$ for beta zeolite). The less steric hindrance in the mesopores of HMCM-41-S and HMCM-48-S, compared to zeolites, probably helps to reach the unique product of lowest energy.

As summarized in Table 3, HMCM-48-SH and HMCM-41-S exhibited much higher catalytic activity in the acylation of anisole with octanoyl chloride than MCM-48. The acidity of the standard MCM-48 is too weak to catalyze the acylation properly. Also, HMCM-48-S shows somewhat higher activity than HMCM-41-S. This is probably due to the easier transport in the bi-continuous channels of the former. More significantly, after treatment in $800{ }^{\circ} \mathrm{C} 20 \%$ steam for $4 \mathrm{~h}$, HMCM-48-S still retains excellent catalytic activity (Fig. 6).

\section{Table 3}

Acylation of anisole with octanoyl chloride on different materials

\begin{tabular}{lll}
\hline Catalyst & $\begin{array}{l}\text { Reaction } \\
\text { time/yield }\end{array}$ & $\begin{array}{l}\text { Reaction } \\
\text { time/yield }\end{array}$ \\
\hline HMCM-48-SH & $1 \mathrm{~h} / 99 \%$ & - \\
$800{ }^{\circ} \mathrm{C} 20 \%$ steam for $4 \mathrm{~h}$ & $2 \mathrm{~h} / 74 \%$ & $6 \mathrm{~h} / 85 \%$ \\
MCM-48 & $1 \mathrm{~h} / 0 \%$ & $1 \mathrm{day} / 9 \%$ \\
HMCM-41-S & $1 \mathrm{~h} / 90 \%$ & $6 \mathrm{~h} / 100 \%$ \\
No catalyst & $1 \mathrm{~h} / 0 \%$ & $4.5 \mathrm{~h} / 0 \%$ \\
\hline
\end{tabular}

Conditions: batch reactor; $T=428 \mathrm{~K}, 0.15 \mathrm{~g}$ catalyst, $0.005 \mathrm{~mol}$ octanoylchloride, and $25 \mathrm{ml}$ anisole.

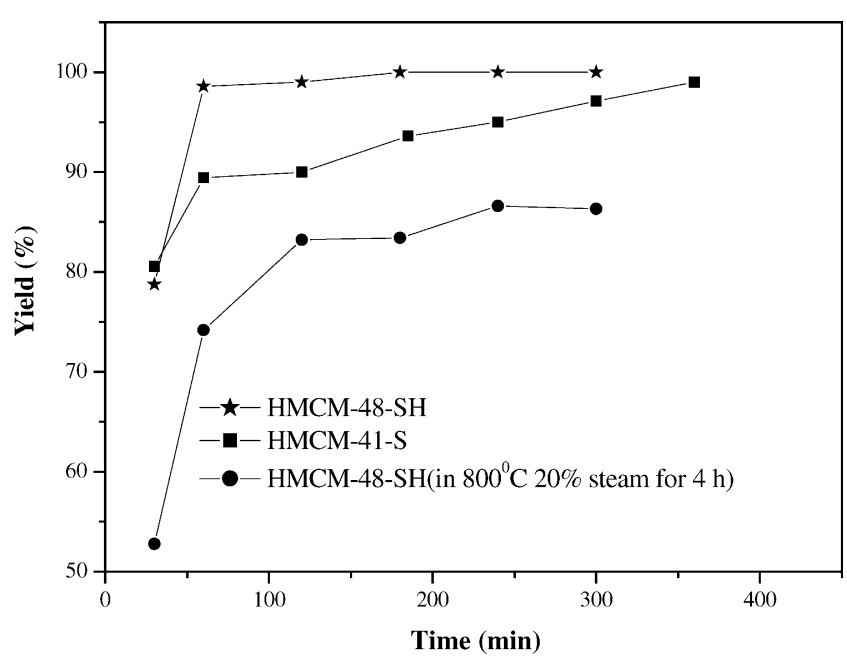

Fig. 6. Acylation of anisole with octanoyl chloride on HMCM-41-S, HMCM-SH, and HMCM-SH (treated in $800^{\circ} \mathrm{C}$ steam for $4 \mathrm{~h}$ ). Conditions: batch reactor; $T=155^{\circ} \mathrm{C}, 0.15 \mathrm{~g}$ catalyst, $0.005 \mathrm{~mol}$ octanoyl chloride, and $25 \mathrm{ml}$ anisole.

We next discuss the merit of using octanoyl chloride versus octanoic acid as the acylation agent. If we used octanoic acid to run the reaction, the reaction is slow and the yield reached only $20 \%$ after $26 \mathrm{~h}$ of reacting (Fig. 7 ). Why is the reaction so inefficient? Because the reaction using octanoic acid produces water. It is generally known that the presence of water can inhibit the active sites on the solid acid catalyst. Beers et al. also found the decrease of the conversion to lower than $20 \%$ when water was not removed. After applying a water-removal scheme, they were able to increase the conversion to $60 \%$ [15].

In summary, mesoporous aluminosilicates (MCM-48-S, MCM-48-SH, and MCM-41-S) with ordered structure have been synthesized using nanocluster seeds of beta zeolites. The materials possess excellent hydrothermal stability and acid strength. The combination of stability, high acid-

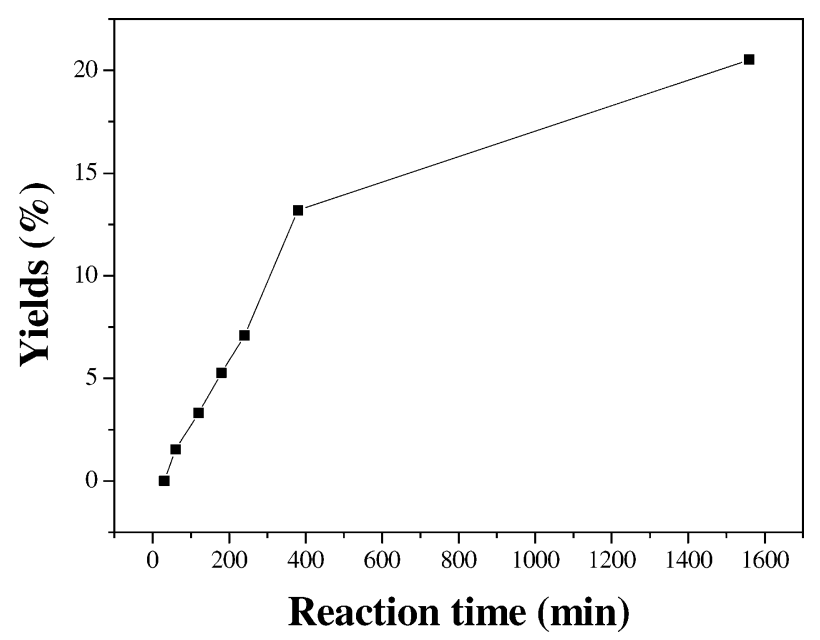

Fig. 7. Acylation of anisole with octanoic acid on HMCM-48-SH. Conditions: batch reactor; $T=155^{\circ} \mathrm{C}, 0.15 \mathrm{~g}$ catalyst, $0.005 \mathrm{~mol}$ octanoic acid, and $25 \mathrm{ml}$ anisole. 
ity, branched channels and tunable structure order makes them excellent materials for applications in catalysis. HMCM-48-SH and HMCM-41-S exhibited higher catalytic activity in the acylation of anisole with octanoyl chloride than MCM-48, which is attributed to the stronger acid sites in HMCM-48-SH and HMCM-41-S.

\section{Acknowledgements}

This work was supported by a grant from the Ministry of Education through Academy Excellent program.

\section{References}

[1] D. Trong On, D. Desplantier-Giscard, C. Danumah, S. Kaliaguine, Appl. Catal. A: Gen. 222 (2001) 299.

[2] (a) Y. Liu, W. Zhang, T.J. Pinnavaia, J. Am. Chem. Soc. 122 (2000) 8791 ;

(b) Y. Liu, T.J. Pinnavaia, J. Mater. Chem. 12 (2001) 3179.

[3] (a) Z. Zhang, Y. Han, L. Zhu, R. Wang, Y. Yu, S. Qiu, D. Zhao, F.S. Xiao, Angew. Chem. Int. Ed. 40 (2001) 1258;

(b) Z. Zhang, Y. Han, F.S. Xiao, S. Qiu, L. Zhu, R. Wang, Y. Yu, Z. Zhang, B. Zou, Y. Wang, H. Sun, D. Zhao, Y. Wei, J. Am. Chem. Soc. 123 (2001) 5014.

[4] Y. Liu, T.J. Pinnavaia, Stud. Surf. Sci. Catal., Parts A and B 142 (2002) 1075.

[5] Y. Liu, T.J. Pinnavaia, Chem. Mater. 14 (2002) 3.

[6] Y. Han, F.S. Xiao, S. Wu, Y. Sun, X. Meng, D. Li, S. Lin, J. Phys. Chem. B 105 (2001) 7963.
[7] P.C. Shih, H.P. Lin, C.Y. Mou, Stud. Surf. Sci. Catal. 146 (2003) 557.

[8] G. Li, Q. Kan, T. Wu, C. Hou, F.S. Xiao, J. Huang, Stud. Surf. Sci Catal. 146 (2003) 149

[9] L. Zhu, F.S. Xiao, Z. Zhang, Y. Sun, Y. Han, S. Qiu, Catal. Today 68 (2001) 209

[10] Y.Y. Sun, Y. Han, L. Yuan, S.Q. Ma, D.H. Jiang, F.S. Xiao, J. Phys. Chem. B 107 (2003) 1853.

[11] G.A. Olah, Friedel-Crafts and Related Reactions, Wiley, New York, 1963.

[12] B. Chiche, A. Finiels, C. Gauthier, P. Geneste, J. Graille, D.J. Pioch, Org. Chem. 51 (1986) 2128.

[13] B. Chiche, A. Finiels, C. Gauthier, P. Geneste, Appl. Catal. 30 (1987) 365.

[14] M. Spagnol, L. Gilbert, E. Benazzi, C. Marcilly, Patent PCT, Int. Appl WO 96, 35 (1996) 655.

[15] A.E.W. Beers, T.A. Nijhuis, F. Kapteijn, J.A. Moulijn, Micropor. Mesopor. Mater. 48 (2001) 279.

[16] A.E.W. Beers, T.A. Nijhuis, N. Aalders, F. Kapteijn, J.A. Moulijn, Appl. Catal. A: Gen. 243 (2003) 237.

[17] A.E.W. Beers, J.A. van Bokhoven, K.M. de Lathouder, F. Kapteijn, J.A. Moulijn, J. Catal. 218 (2003) 239.

[18] S. Jun, J.M. Kim, R. Ryoo, Y.S. Ahn, M.H. Han, Micropor. Mesopor Mater. 41 (2000) 119

[19] C. Defosse, P. Canesson, J. Chem. Soc., Faraday Trans. 1 (1976) 2565.

[20] R. Borade, A. Clearfield, J. Phys. Chem. 96 (1992) 6729.

[21] R. Borade, A. Sayari, A. Adnot, S. Kaliaguine, J. Phys. Chem. 94 (1990) 5989.

[22] J.G. Santiesteban, J.C. Vartuli, S. Han, R.D. Bastian, C.D. Chang, J. Catal. 168 (1997) 431. 